\title{
Genomic Changes in an Attenuated ZB Strain of Foot-and-Mouth Disease Virus Serotype Asial and Comparison with Its Virulent Parental Strain
}

\author{
Aiguo Xin, ${ }^{1}$ Mingwang Zhu, ${ }^{2}$ Zhenqi Peng, ${ }^{2}$ Qi Hu, ${ }^{1}$ Chenhong Shi, ${ }^{2}$ \\ Defang Liao, ${ }^{1}$ Jihua Wang, ${ }^{2}$ and Huachun $\mathrm{Li}^{1}$ \\ ${ }^{1}$ Yunnan Tropical and Subtropical Animal Virus Disease Laboratory, Yunnan Animal Science and Veterinary Institute, \\ Kunming 650224, China \\ ${ }^{2}$ Yunnan Provincial Research Center for Veterinary Biological Products, Baoshan 678000, China \\ Correspondence should be addressed to Aiguo Xin; aiguo_xin@hotmail.com and Huachun Li; huachun_li@hotmail.com
}

Received 27 May 2014; Revised 18 September 2014; Accepted 22 September 2014; Published 19 October 2014

Academic Editor: Graziano Pesole

Copyright ( 2014 Aiguo Xin et al. This is an open access article distributed under the Creative Commons Attribution License, which permits unrestricted use, distribution, and reproduction in any medium, provided the original work is properly cited.

\begin{abstract}
The molecular basis of attenuation of foot-and-mouth disease virus (FMDV) serotype Asial ZB strain remains unknown. To understand the genetic changes of attenuation, we compared the entire genomes of three different rabbit-passaged attenuated $\mathrm{ZB}$ strains (ZB/CHA/58(att), ZBRF168, and ZBRF188) and their virulent parental strains (ZBCF22 and YNBS/58). The results showed that attenuation may be brought about by 28 common amino acid substitutions in the coding region, with one nucleotide point mutation in the $5^{\prime}$-untranslated region $\left(5^{\prime}\right.$-UTR) and another one in the $3^{\prime}$-UTR. In addition, a total of 21 nucleotides silent mutations had been found after attenuation. These substitutions, alone or in combination, may be responsible for the attenuated phenotype of the ZB strain in cattle. This will contribute to elucidation of attenuating molecular basis of the FMDV ZB strain.
\end{abstract}

\section{Introduction}

Foot-and-mouth disease (FMD) is a highly infectious disease of cloven-hoofed animals. The causative agent, foot-andmouth disease virus (FMDV), is a member of the genus Aphthovirus within the family Picornaviridae and has seven serotypes: O, A, C, Asial, and Southern African Territories (SAT) 1, SAT2, and SAT3 [1, 2]. Infection or vaccination with one serotype of FMDV does not protect against other serotypes [3]. The FMDV genome includes a single open reading frame (ORF) flanked by $5^{\prime}$ and $3^{\prime}$ untranslated regions, $5^{\prime}$-UTR and $3^{\prime}$-UTR. Upon infection, the viral RNA is translated into a single polyprotein that is concurrently processed by three virus-encoded proteinases, leader $\left(\mathrm{L}^{\mathrm{pro}}\right), 2 \mathrm{~A}$, and $3 \mathrm{C}^{\text {pro }}$ into precursors and consequent mature structural (VP1, VP2, VP3, and VP4) and nonstructural ( $\mathrm{L}^{\mathrm{pro}}, 2 \mathrm{~A}, 2 \mathrm{~B}$, $2 \mathrm{C}, 3 \mathrm{~A}, 3 \mathrm{~B}, 3 \mathrm{C}^{\mathrm{pro}}$, and $3 \mathrm{D}^{\mathrm{pol}}$ ) proteins $[4,5]$.

In the late 1950s, a FMD-like disease occurred in Baoshan county, Yunnan province, China. A virus related to the outbreak was isolated and named as the FMDV ZB (Zhongguo
Baoshan) strain. Subsequently, a live attenuated vaccine was developed by serial passaging wild-type virulent ZB strain in suckling rabbits for more than 100 passages, in order to prevent FMD Asial outbreaks on the border between China and Myanmar from 1960s to 1990s. A review of the passaging history of the virulent ZB strain attenuation process revealed that the virus after the 60th passage still caused clinical FMD but did not cause visible clinical symptoms in cattle after 109 th passage. The virus passaged to the 114th passage was therefore used as a live vaccine after its safety and efficacy were confirmed.

However, the criteria for the selection of the attenuated strain were highly empirical, and little is known about the molecular mechanisms causing attenuation. The complete genome sequence of the attenuated strain and its virulence determinants must be clear for quality control of the vaccine. Although the entire genomes of a cell-culture rabbitattenuated $\mathrm{ZB} / \mathrm{CHA} / 58$ (att) strain and an inactivated vaccine YNBS/58 strain deriving from the same origin of ZB strain [6] had been previously compared, the virulence determinants 
TABLE 1: Primers used for amplification of the FMDV ZB strain genome.

\begin{tabular}{llcc}
\hline Primer & Sequence $\left(5^{\prime}-3^{\prime}\right)$ & Fragment & Coordinates $^{\mathbf{a}^{2}}$ \\
\hline F1 & TTGAAAGGGGGCGCTAGGTCT & F1 & $1-22$ \\
R1011 & CCTATTCAGGCGTAGAAGCTT & F1 & $991-1011$ \\
F916 & CACTGGTGACAGGCTAAGGATG & F2 & $887-908$ \\
R2383 & CCGTCATGTTGGTGCGTGGGTT & F2 & $2363-2384$ \\
F1608 & ACGATCAGGAACCACTCAACG & F3 & $1608-1628$ \\
R4100 & AGCTTGTACCAGGGTTTGGC & F3 & $4081-4100$ \\
F3970 & CAGATGCAGGAGGACATGTC & F4 & $3970-3989$ \\
R6434 & AGAGGCCAGGCATGGTGTC & F4 & $6406-6424$ \\
F5404 & GAAAGGCCAACACGAAGCAGC & F5 & $5373-5393$ \\
R6944 & TCCATGGCGTCAAGTCCGTCGACGC & F5 & $6920-6944$ \\
F6610 & GGGTTGATCGTTGACACCAGAGA & F6 & F6 \\
RES-dT 18 & GCGGCCGCGATATCT & & Poly A \\
\hline
\end{tabular}

${ }^{a}$ Nucleotides position corresponds to the nucleotide sequence of the ZB/CHA/58(att) (GenBank number DQ533483).

of the ZB strain have not been elucidated. A total of 25 amino acid substitutions were observed between strains ZB/CAH/58(att) and YNBS/58 [7]. Therefore, we compared the entire genomes of three different rabbit-passaged attenuated ZB strains (ZB/CHA/58(att), ZBRF168, and ZBRF188) and their virulent parental viruses (ZBCF22 and YNBS/58), in order to identify genomic changes that occurred during the attenuation process of the $\mathrm{ZB}$ strain.

\section{Materials and Methods}

2.1. Viruses. Virulent FMDV Asial ZBCF22 strain was passaged 22 times in cattle via needle inoculation and then passaged on tongue epithelium in Baoshan County, China. It was maintained as a challenge virus strain at Yunnan Provincial Research Center for Veterinary Biological Products. The attenuated ZBRF168 and ZBRF188 strains were derived from virulent parental $\mathrm{ZBCF} 22$ strain via consecutive passage for 168 or 188 times in suckling rabbits following the established protocol [8] with modifications. Briefly, a 5-day-old suckling rabbit was subcutaneously inoculated with the viral agent. The rabbits showed clinical signs of short breath and leg paralysis 16-20 hrs after inoculation and died between 18 and $28 \mathrm{hrs}$. The carcasses of dead rabbits were harvested and homogenized in PBS buffer at 1/10 (w/v) followed by clarification by centrifugation at $1000 \mathrm{~g}$ for $30 \mathrm{~min}$. The supernatant containing the viral agent was then used as inoculums for the next passage. $\mathrm{ZB} / \mathrm{CHA} / 58$ (att) strain is a cell-adapted rabbit-attenuated strain that was passaged 187 times in suckling rabbits and adapted to BHK-21 cells. These attenuated strains are stored at the Yunnan Animal Science and Veterinary Institute.

2.2. FMDV RNA Extraction and Reverse Transcription Polymerase Chain Reaction (RT-PCR). FMDV RNAs were extracted using the RNAiso Plus (TaKaRa Biotechnology Co. Ltd., Dalian, China) and used immediately for cDNA synthesis. Synthesis of cDNA was carried out using 6 random primers and Superscript II reverse transcriptase (Invitrogen, USA). Six cDNA fragments covering the entire
FMDV genome were amplified by PCR using six primer sets (Table 1). PCR amplifications with Pyrobest Pfu polymerase (TaKaRa Biotechnology Co. Ltd., Dalian, China) were performed according to the manufacturer's protocol. For PCR amplification, PCR reaction conditions were as follows: 1 cycle predenaturation for $5 \mathrm{~min}$ at $95^{\circ} \mathrm{C}, 30$ cycles for amplification at $94^{\circ} \mathrm{C}$ for $30 \mathrm{sec}, 58^{\circ} \mathrm{C}$ (for $\mathrm{F} 1$ fragment) or $52^{\circ} \mathrm{C}$ (for F2, F3, F4, F5, and F6 fragment) for $30 \mathrm{sec}, 72^{\circ} \mathrm{C}$ for $1 \mathrm{~min}$ (for F1) or $3 \mathrm{~min}$ (for F2, F3, F4, F5, and F6), and 1 cycle for final extension at $72^{\circ} \mathrm{C}$ for $10 \mathrm{~min}$. The PCR products were purified from agarose gel electrophoresis and sequenced directly using a ABI-PRIS MTM 377XL DNA Sequencer at two companies, Sangon Biotech (Shanghai, China) and Taihe Biotech (Beijing, China). The genomic sequences were sequenced twice at each of the companies.

2.3. Sequence Analysis. FMDV reference sequences were acquired from the GenBank database of the National Center for Biotechnology Information (http://www.ncbi.nlm.nih .gov/). The sequence data were assembled using the program Assemble (Vector NTI 8.0 suite, InforMax, North Bethesda, MD, USA). Multiple sequence alignments were performed using a ClustalX multiple sequence alignment program, version 1.83 [9]. A phylogenetic tree was constructed by the neighbor-joining method with the Kimura 2-parameter nucleotide substitution method using 1000 bootstrap replicates in the MEGA version 3.1 [10]. RNA secondary structure was extrapolated using the RNA structure 4.6 software.

\section{Results and Discussion}

3.1. Genomic Organization of ZB Strains and Phylogenetic Analysis. The genome sequences of the virulent ZBCF22 and the rabbit-attenuated strains (ZBRF168 and ZBRF188) were determined to be 8,164 nucleotides (nt) in length (excluding the poly-C and poly-A tracts) and contain an ORF of 6,990 nt that encodes a polyprotein of 2,329 amino acids, which is consistent with the previously reported $\mathrm{ZB} / \mathrm{CHA} / 58$ (att) genome [7]. The ORFs of these strains were shown to be flanked by a $5^{\prime}$-UTR of $1,081 \mathrm{nt}$ and a $3^{\prime}$-UTR of $93 \mathrm{nt}$. 


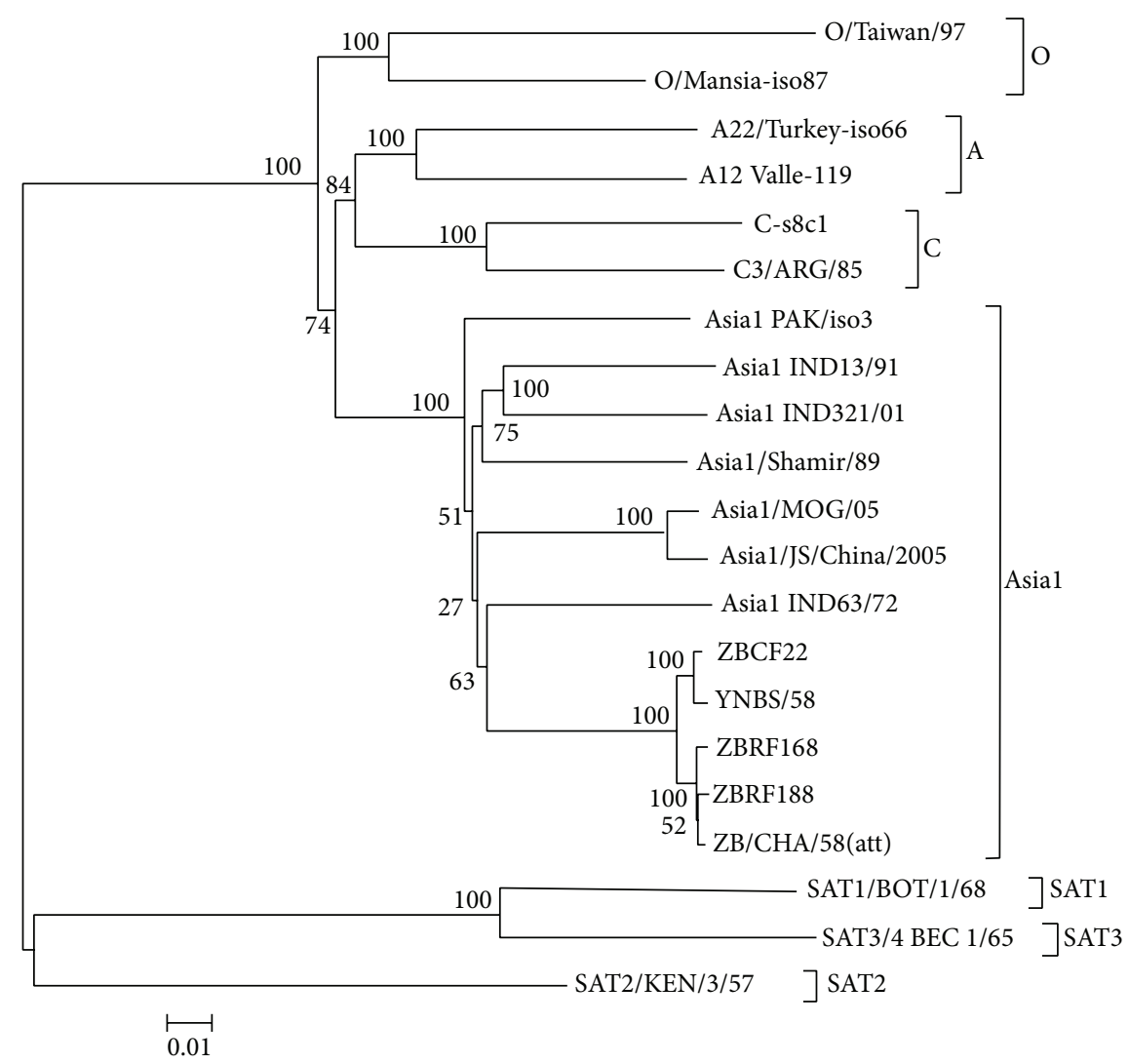

Figure 1: Phylogenetic analysis of the FMDV genome sequences. Phylogenetic tree was constructed by the neighbor-joining method by using MEGA 3.1, and bootstrap values were determined by 1,000 replicates. The GenBank accession numbers of 16 reference strains are listed as follows. O Taiwan/97(AY593835), O/Manisa-iso87(AY593823), A12 Valle strain-119(AY593752), A22 Turkey/65-iso66(AY593765), C1/C-s8cl(AJ133357), C3/Arg/85(AJ007347), SAT1 BOT/1/68(AY593845), SAT2/KEN/57(AY251473), SAT3/4 BEC 1/65(AY593853), Asial PAK/iso3(AY593795), Asial IND 13/91(DQ989312), Asial IND321/01(AY687333), Asial/Shamir/89(JF739177), Asia1/MOG/05(EF614458), Asial/JS/CHA/05(EF149009), Asia1/IND 63/72(AY304994), YNBS/58(AY390432), and ZB/CHA/58(att)(DQ533483).

A neighboring-joining (NJ) tree construct was based on the sequence alignment of 21 selected genomes, which were distinctly divided into seven serotypes of FMDV and the ZB strains were tightly clustered in the Asial serotype (Figure 1). The results demonstrate that $\mathrm{ZB}$ strains belong to the FMDV serotype Asial from the perspective of comparative genomics.

3.2. Comparison of the Untranslated Region Sequences of Different FMDV Strains. The nucleotide sequences were compared for the three attenuated $\mathrm{ZB}$ strains, the two virulent strains, and other FMDV Asial reference strains. Observed differences in the $5^{\prime}$-UTR between the virulent and attenuated ZB strains were limited, with only one common nucleotide mutated in the internal ribosome entry site (IRES) region (C573-G) (Table 2). The critical role of the IRES element in mediating efficient translation of the viral RNA suggests that this mutation may be involved in the attenuated phenotypes of the ZB strains, presumably through a disruption of RNA secondary structure of IRES. It has been reported that FMD virus after 100 passages in BHK-21 cells carried two point mutations in the IRES and showed increased virulence in cells [11]. In contrast, previous studies have shown that nucleotides changes in the UTR between virulent and attenuated FMDV strains (i.e., strains O1 Campos and C3 Resende) may not be the key determinants of egg-adapted attenuated FMDVs [12]. The FMDV $3{ }^{\prime}$-UTR was predicted to fold into two well-defined stem-loop (SL) structures, highly conserved among isolates and essential for viral infection and IRES activity [13]. Of the two, the first stem-loop (SL1) is to be dispensable for infectivity acting as a replication enhancer [14]. In the genomes of ZBCF22 and ZB/CHA/58(att) strains, guanine was located at the 24 position of SL1 in $3^{\prime}$-UTR (Figure 2), but guanine was replaced by adenine (Table 2) in the genomes of the ZBRF168 and ZBRF188 strains. We conclude that this noncommon mutation in the $3^{\prime}$-UTR is unlikely to be involved in the process of the attenuation.

3.3. Comparison of the Protein Coding Regions of FMDVs. Comparison of the protein coding regions between the virulent and attenuated ZB strains revealed no deletion/insertion mutations. A total of 33 amino acid substitutions were observed scattered across nine proteins ( $\mathrm{L}^{\text {pro }}, \mathrm{VP} 2, \mathrm{VP} 1,2 \mathrm{~A}$, $2 \mathrm{~B}, 2 \mathrm{C}, 3 \mathrm{~A}, 3 \mathrm{C}^{\mathrm{pro}}$, and $3 \mathrm{D}^{\mathrm{pol}}$ ). Five of them (VP2: D133-G, VP1: P146-F, G155-R, 2A: K8-E, and 3A: A51-G) only existed in the rabbit-attenuated $\mathrm{ZB} / \mathrm{CHA} / 58$ (att) strain, whereas 28 common amino acid changes were found during the process 
TABLE 2: Nucleotide mutations of ZBCF22 and their attenuated strains in untranslated regions (UTRs) ${ }^{\dagger}$.

\begin{tabular}{lccccccc}
\hline Region & Position $^{*}$ & ZBCF22 & ZBRF168 & ZBRF188 & ZB/CHA/58(att) & YNBS/58 & Corresponding residue in ref. \\
\hline $5^{\prime}$-UTR & 573 & C & G & G & G & C & G \\
$3^{\prime}$-UTR & 24 & G & A & A & G & G & G \\
\hline
\end{tabular}

${ }^{\dagger}$ Excluding poly $(\mathrm{C})$ tract in the $5^{\prime}$-UTR fragment.

${ }^{*}$ Nucleotides position corresponds to the nucleotide sequence of the ZB/CHA/58(att).

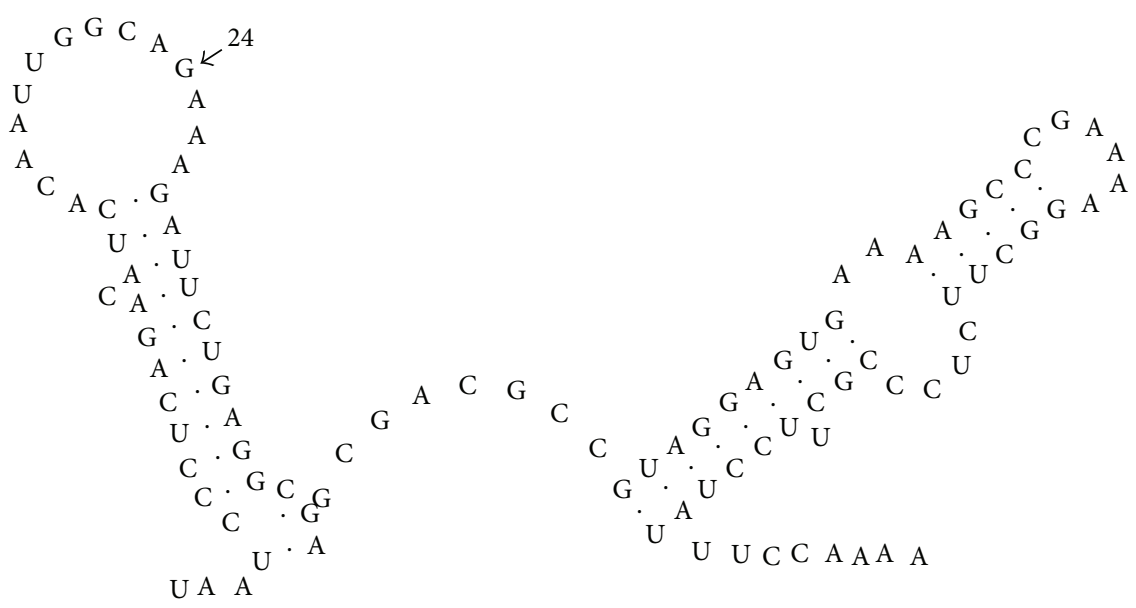

FIgURE 2: The 3' -UTR RNA secondary structure of FMDV ZBCF22 strain.

of attenuation of the ZB strains. No amino acid changes in the VP4, VP3, and 3B protein had been found after attenuation (Table 3 ). In addition, a total of 21 characteristic nucleotide substitutions, all of which produce silent mutations, were found scattered across ten proteins ( $\mathrm{L}^{\text {pro }}, \mathrm{VP} 4, \mathrm{VP} 2, \mathrm{VP} 3$, VP1, 2B, 2C, 3A, 3B, and 3D $\mathrm{D}^{\text {pol }}$ ) (Table 4).

In protease $3 \mathrm{C}^{\text {pro }}$ of the $\mathrm{ZB}$ strains, a common substitution V74-I was observed during the attenuation process, which was identical to the other FMDV Asial reference strains (Table 3). Residue V74-I substitution might not be essential for attenuation since both amino acids belong to the same hydrophobic group, although FMDV $3 C^{\text {pro }}$ is critical for viral pathogenesis and plays vital roles in both the processing of the polyprotein precursor and RNA replication $[15,16]$. In fact, proteases play an essential role in viral polyprotein processing and have been shown to be important virulence determinants in many pathogens [17-19]. In protease $L^{\text {pro }}$ of $\mathrm{ZB}$ strains, three common amino acid changes (N2-D, M143-L, and E147-G) have been found. Two of them (N2$\mathrm{D}$ and E147-G) changed the charges of the amino acids and thus may likely contribute to the attenuated phenotype of $\mathrm{ZB}$ strains. Residue N2-D substitution was located at the interAUG region of FMDV, which has been associated in the attenuation of FMDV A24 strain [20]. FMDV L ${ }^{\text {pro }}$ was shown to be a virulence determinant based on experiments with $L^{\text {pro }}$ lacking virus, which is highly attenuated in cattle and pig $[21,22]$ and not required for viral replication $[16] . \mathrm{L}^{\text {pro }}$ plays a central role in pathogenesis through regulation affecting the host innate immune response [23-25]. Residue L143 of the FMDV $\mathrm{L}^{\text {pro }}$ is a determinant of cleavage specificity, but a hydrophobic residue $(\mathrm{M} / \mathrm{L})$ substitution in the $\mathrm{L}^{\text {pro }}$ may not be the key virulence determinant for the $\mathrm{ZB}$ strain attenuation [26].

In the conserved RNA-dependent RNA polymerase $3 \mathrm{D}^{\mathrm{pol}}$, three common amino acid changes (R84-H, V158-A, and $\mathrm{H} 378-\mathrm{Q})$ were found after attenuation by passaging in vivo. However, four picornaviral polymerase peptide motifs KDELR, PSG, YGGD, and FLKR [27, 28] were conserved among the virulent and attenuated $\mathrm{ZB}$ strains, and three hypervariable and hydrophobic antigenic regions (aa 1 to 12 , 64 to 76 , and 143 to 145 ) were also stable in all ZB strains $[29,30]$. Furthermore, it has been recently reported that the $\mathrm{R} 84-\mathrm{H}$ mutant is a high fidelity variant and does not correlate with virus attenuation [31]. We suspect that residues R84$\mathrm{H}$ and V158-A substitutions are not the key determinants of attenuation, but that the H378-Q mutation (a basic amino acid changed to an amide amino acid) may be related to the attenuation of $\mathrm{ZB}$ strains in cattle.

In the structural protein $\mathrm{P} 1-2 \mathrm{~A}$ region of the $\mathrm{ZB}$ strains, no substitution was observed in the VP4 or VP3 protein after the attenuation process. It was previously reported that residue $\mathrm{R} 56-\mathrm{H}$ substitution in the VP3 of O1Campos strain could lead to thermostability and induced typical clinical signs of FMD [32]. We found that a common substitution (V184-L) in the VP2 protein of the ZB strains located at the previously identified T-cell epitopes (aa 179 to 187) [33]. FMDV VP2 associates mainly with virion structural stability and maturation [34]. Therefore, considering that valine and leucine residue share the same amino acid properties, we assume that substitution V184-L may not play a critical role in the attenuation of the $\mathrm{ZB}$ strains.

The highest mutation rate was found in the VP1 protein with eight amino acid substitutions during the attenuation 
TABLE 3: Comparison of amino acid differences in the protein coding region between the virulent and attenuated ZB strains.

\begin{tabular}{|c|c|c|c|c|c|c|c|}
\hline Region & Position $^{*}$ & ZBCF22 & ZBRF168 & ZBRF188 & $\mathrm{ZB} / \mathrm{CHA} / 58$ (att) & YNBS/58 & Corresponding residue in ref. $^{\dagger}$ \\
\hline \multirow{3}{*}{$\mathrm{L}^{\text {pro }}$} & 2 & $\mathrm{~N}$ & $\mathrm{D}$ & $\mathrm{D}$ & $\mathrm{D}$ & $\mathrm{N}$ & $\mathrm{N}$ \\
\hline & 143 & M & $\mathrm{L}$ & $\mathrm{L}$ & $\mathrm{L}$ & M & M \\
\hline & 147 & $\mathrm{E}$ & G & G & G & $\mathrm{E}$ & $\mathrm{E}$ \\
\hline \multirow{2}{*}{ VP2 } & 133 & $\mathrm{D}$ & $\mathrm{D}$ & $\mathrm{D}$ & G & $\mathrm{D}$ & $\mathrm{D}$ \\
\hline & 184 & $\mathrm{~V}$ & $\mathrm{~L}$ & $\mathrm{~L}$ & $\mathrm{~L}$ & $\mathrm{~V}$ & $\mathrm{~V}$ \\
\hline \multirow{8}{*}{ VP1 } & 4 & A & $\mathrm{T}$ & $\mathrm{T}$ & $\mathrm{T}$ & A & $\mathrm{A} / \mathrm{T}$ \\
\hline & 21 & A & $\mathrm{E}$ & $\mathrm{E}$ & $\mathrm{E}$ & A & $\mathrm{E}$ \\
\hline & 45 & $\mathrm{P}$ & $\mathrm{L}$ & $\mathrm{L}$ & $\mathrm{L}$ & $\mathrm{P}$ & $\mathrm{P}$ \\
\hline & 81 & A & $\mathrm{V}$ & $\mathrm{V}$ & $\mathrm{V}$ & A & $\mathrm{V}$ \\
\hline & 142 & S & $\mathrm{R}$ & $\mathrm{R}$ & $\mathrm{R}$ & $S$ & $\mathrm{M} / \mathrm{R}$ \\
\hline & 146 & $\mathrm{P}$ & $\mathrm{P}$ & $\mathrm{P}$ & $\mathrm{F}$ & $\mathrm{P}$ & $\mathrm{R} / \mathrm{L} / \mathrm{M}$ \\
\hline & 147 & $S$ & A & A & A & $S$ & A \\
\hline & 155 & G & G & G & $\mathrm{R}$ & G & K/N/G/A \\
\hline $2 \mathrm{~A}$ & 8 & $\mathrm{~K}$ & $\mathrm{~K}$ & K & E & K & $\mathrm{K}$ \\
\hline \multirow{3}{*}{$2 \mathrm{~B}$} & 19 & $\mathrm{~N}$ & $S$ & $S$ & $S$ & $\mathrm{~N}$ & $\mathrm{~N}$ \\
\hline & 74 & A & $\mathrm{T}$ & $\mathrm{T}$ & $\mathrm{T}$ & A & A \\
\hline & 136 & $\mathrm{~V}$ & I & I & I & $\mathrm{V}$ & $\mathrm{V}$ \\
\hline \multirow{5}{*}{$2 \mathrm{C}$} & 6 & V & I & I & I & V & I \\
\hline & 64 & K & E & $\mathrm{E}$ & $\mathrm{E}$ & K & K \\
\hline & 135 & $\mathrm{~T}$ & $\mathrm{~T}$ & I & I & $\mathrm{T}$ & $\mathrm{T}$ \\
\hline & 248 & I & $\mathrm{T}$ & $\mathrm{T}$ & $\mathrm{T}$ & $\mathrm{T}$ & $\mathrm{I} / \mathrm{L}$ \\
\hline & 313 & $\mathrm{Y}$ & $\mathrm{H}$ & $\mathrm{H}$ & $\mathrm{H}$ & $\mathrm{Y}$ & $\mathrm{H}$ \\
\hline \multirow{7}{*}{$3 \mathrm{~A}$} & 51 & A & A & A & G & A & A \\
\hline & 78 & $\mathrm{E}$ & G & G & G & $\mathrm{E}$ & $\mathrm{E}$ \\
\hline & 80 & $\mathrm{H}$ & C & C & $\mathrm{C}$ & $\mathrm{H}$ & $\mathrm{R}$ \\
\hline & 84 & $\mathrm{~K}$ & $\mathrm{~N}$ & $\mathrm{~N}$ & $\mathrm{~N}$ & $\mathrm{~K}$ & K/Q \\
\hline & 97 & A & $\mathrm{P}$ & $\mathrm{P}$ & $\mathrm{P}$ & A & A \\
\hline & 107 & $\mathrm{D}$ & $\mathrm{D}$ & $\mathrm{N}$ & $\mathrm{N}$ & $\mathrm{D}$ & $\mathrm{D}$ \\
\hline & 127 & $\mathrm{R}$ & I & I & I & $\mathrm{R}$ & $\mathrm{R}$ \\
\hline $3 C^{\text {pro }}$ & 74 & $\mathrm{~V}$ & I & $\mathrm{I}$ & I & $\mathrm{V}$ & I \\
\hline \multirow{3}{*}{$3 \mathrm{D}^{\mathrm{pol}}$} & 84 & $\mathrm{R}$ & $\mathrm{H}$ & $\mathrm{H}$ & $\mathrm{H}$ & $\mathrm{R}$ & $\mathrm{R}$ \\
\hline & 158 & $\mathrm{~V}$ & A & A & A & $\mathrm{V}$ & $\mathrm{A} / \mathrm{V}$ \\
\hline & 378 & $\mathrm{H}$ & Q & Q & Q & $\mathrm{H}$ & $\mathrm{H}$ \\
\hline
\end{tabular}

${ }^{*}$ The amino acids listed are at equivalent positions of ZB/CHA/58(att) (GenBank number DQ533483).

${ }^{\dagger}$ The FMDV serotype Asial reference strains are YNBS/58(AY390432), PAK/54(AY593795), IND63/72(304994), IND 321/01(AY687333), IND 491/97 (AY687334), ISRL13/63(AY593796), Asial/3 Kimorn(AY593797), and Leb 3/83(AY593798).

process of the ZB strains (Table 3). Four of them (A4-T, P45L, A81-V, and S147-A) included amino acids with similar nature, while two others (A21-E and S142-R) resulted in a change of amino acids charge. It was previously proposed that changes of viral surface may play an important role in attenuation process. Therefore, VP1 is likely to be the protein for attenuating mutations. Indeed, a recent study demonstrated that the capsid proteins of the O1Kaubeuren B64 strain were responsible for its attenuation in cattle [35]. Moreover, the adaptive replacement of L147-P in VP1 of the guinea pig-adapted $\mathrm{C}-\mathrm{S} 8 \mathrm{cl}$ strain abolished growth of the virus in different established cell lines and modified its antigenicity [36]. Additionally, substitution of D143-A in the G-H loop antigenic site (VP1 residues 138 to 150) abolished infectivity of virus in suckling mice [37]. After ZB strain attenuation, the influence of the S142-R change in the -1 position and S147-A change in the +2 position of RGD is not clear (Figure 3(a)). The amino acid substitutions around the RGD motif suggest advantages of these substitutions in host cell recognition and binding during the attenuation process of the $\mathrm{ZB}$ strains. It is conceivable that these amino acid substitutions may modify the surface properties of the virion in a way that may reduce its virulence in cattle. The amino acids immediately following the RGD motif have a major influence on the ability of the different integrin species, and $\mathrm{RGD}+1$ position is important in the receptor recognition process [38]. Residue phenylalanine at $R G D+1$ position of the cell-adapted rabbit-attenuated $\mathrm{ZB} / \mathrm{CHA} / 58$ (att) was different in other $\mathrm{ZB}$ strains, suggesting that this substitution may be associated with the cell adaptation in BHK-21 cells. 


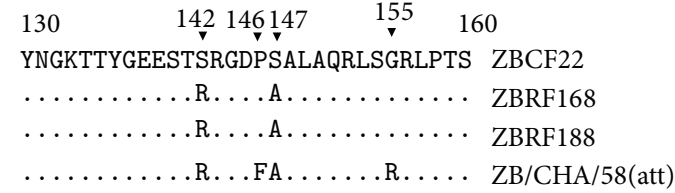

(a)

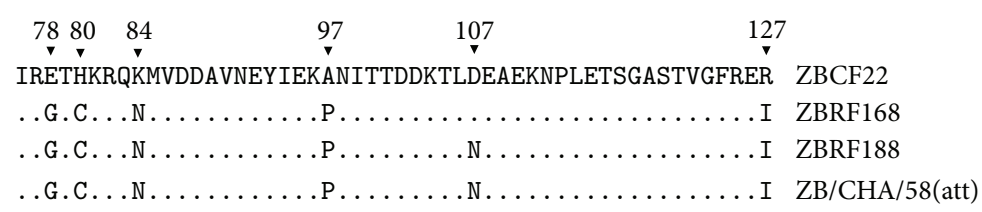

(b)

FIGURE 3: Comparison of amino acid differences between the ZB virulent and attenuated strains: (a) VP1 antigen site B (aal30-160) and (b) $3 \mathrm{~A}($ aa76-127).

TABLE 4: Synonymous nucleotides substitutions in the protein coding region between the virulent and attenuated $\mathrm{ZB}$ strains.

\begin{tabular}{lccc}
\hline Region & Position $^{*}$ & Virulent strains $^{\dagger}$ & Attenuated strains $^{\dagger}$ \\
\hline \multirow{2}{*}{ L $^{\text {pro }}$} & 1339 & GCA & GCG \\
& 1421 & CTG & TTG \\
& 1630 & GTG & GTA \\
\hline VP4 & 1807 & CAG & CAA \\
\hline \multirow{2}{*}{ VP2 } & 2074 & GAC & GAT \\
& 2263 & GGC & GGG \\
& 2575 & GTA & GTG \\
\hline \multirow{2}{*}{ VP3 } & 2980 & GTG & GTA \\
& 3019 & GTG & GTA \\
& 3076 & TCT & TCC \\
\hline VP1 & 3169 & ATT & ATC \\
\hline $2 B$ & 3691 & CGT & CGC \\
\hline \multirow{2}{*}{2 C } & 4132 & CTC & CTT \\
& 4684 & GCT & GCC \\
\hline $3 A$ & 4918 & TTC & TTT \\
\hline \multirow{2}{*}{$3 \mathrm{~B}$} & 5029 & CTA & CTG \\
\hline \multirow{2}{*}{$3 D^{\text {pol }}$} & 7377 & CAG & CAA \\
\hline
\end{tabular}

${ }^{*}$ The nucleotides listed are at equivalent positions of $\mathrm{ZB} / \mathrm{CHA} / 58$ (att) (GenBank number DQ533483). Nucleotide changes are indicated in bold.

${ }^{\dagger}$ The virulent FMDV ZB strains included ZBCF22 and YNBS/58, and the attenuated strains included ZBRF168, ZBRF188, and ZB/CHA/58(att).

In the FMDV genomic P2 region, during the virulent $\mathrm{ZB}$ strain attenuation process, three common residues with a similar nature (N19-S, A74-T, and V136-I) of substitutions were found in 2B (Table 3), making their influence in attenuation difficult to assess. FMDV $2 \mathrm{~B}$ protein is an integral membrane protein and localizes to endoplasmic reticulumderived outer surface vesicles which are sites of genome replication [39]. In the $2 \mathrm{C}$ protein, four common amino acid substitutions were observed after attenuation (Table 3), and we suspect that amino acid substitutions K64-E and $\mathrm{Y} 313-\mathrm{H}$ play a role in viral virulence by interactions with several host factors during infection. FMDV 2C, with ATPase activity, localizes to membrane-associated virus-replicating complexes [39]. The $2 \mathrm{C}$ protein in the hepatitis $\mathrm{A}$ virus is one of the virulence genes in this virus [40]. In the case of the FMDV C-S8cl strain, residue T248-I mutation in 2C was not required for virulence of virus adaptation to infect the guinea pig [41], and residue R55-W mutation in 2C had regained competence in plaque development on BHK21 [42].

In the $3 \mathrm{~A}$ protein, sequence analysis showed that no deletion or insertion mutations existed between the attenuated ZB strains and their parental viruses, while five common amino acid mutations were observed (Table 3). A residue substitution (A51-G) was only found in ZB/CHA/58(att), and another substitution (D107-N) was found in ZBRF188 and $\mathrm{ZB} / \mathrm{CHA} / 58$ (att) (Figure 3(b)). We propose that these amino acid substitutions are likely to be the major determinants of attenuation, especially residues E78-G, H80-C, K84-N, and R127-I, which will result in a less charged and more hydrophobic $3 \mathrm{~A}$ protein than the one in virulent $\mathrm{ZBCF} 22$. Residue E78-G substitution was also observed in the FMDV R strain and its chick-attenuated R304 strain [43]. It was previously demonstrated that the Q44-R amino acid substitution in $3 \mathrm{~A}$ of FMDV strain C-S8cl can mediate adaptation of FMDV to the guinea pig [41]. The $3 \mathrm{~A}$ protein has been found to be associated with bovine attenuation of egg-adapted FMDV [44], and deletions in 3A have been shown to be associated with FMDV attenuation in cattle and high virulence in pigs $[45,46]$. It was recently shown that the partial deletion in $3 \mathrm{~A}$ can attenuate FMDV in cattle [47]. It would be interesting to examine by reverse genetics if these amino acid substitutions in the $3 \mathrm{~A}$ protein of the $\mathrm{ZB}$ strain may contribute to an attenuation phenotype in cattle.

In conclusion, we identified genomic changes between the virulent and attenuated FMDV ZB strains in the untranslated regions, as well as in the protein coding regions, and discussed those changes correlated with the virus attenuation in context of the current knowledge of the FMDV's molecular biology. Study data indicated that candidate amino acid substitutions might play roles in the attenuation phenotype of the $\mathrm{ZB}$ strains. However, determining which and how those amino acid substitutions are directly involved in the attenuation of the virulent viruses will require animal experiments and cell infections to determine the pathogenesis of different mutated viruses. We are now using reverse genetic approaches to construct a series of mutants to confirm the virulent determinants during the attenuation process.

\section{Conflict of Interests}

The authors declare that there is no conflict of interests regarding the publication of this paper. 


\section{Acknowledgments}

This work was jointly supported by grants from the National Natural Science Foundation of China (no. 31060343) and the Innovative Talents in Science and Technology Project of Yunnan province (2011HB035).

\section{References}

[1] M. J. Grubman and B. Baxt, "Foot-and-mouth disease," Clinical Microbiology Reviews, vol. 17, no. 2, pp. 465-493, 2004.

[2] E. Domingo, C. Escarmís, E. Baranowski et al., "Evolution of foot-and-mouth disease virus," Virus Research, vol. 91, no. 1, pp. 47-63, 2003.

[3] S. Parida, "Vaccination against foot-and-mouth disease virus: strategies and effectiveness," Expert Review of Vaccines, vol. 8, no. 3, pp. 347-365, 2009.

[4] G. J. Belsham, "Distinctive features of foot-and-mouth disease virus, a member of the picornavirus family; aspects of virus protein synthesis, protein processing and structure," Progress in Biophysics and Molecular Biology, vol. 60, no. 3, pp. 241-260, 1993.

[5] M. D. Ryan, G. J. Belsham, and A. M. Q. King, "Specificity of enzyme-substrate interactions in foot-and-mouth disease virus polyprotein processing," Virology, vol. 173, no. 1, pp. 35-45, 1989.

[6] J. Du, H. Chang, G. Cong et al., "Complete nucleotide sequence of a Chinese serotype Asial vaccine strain of foot-and-mouth disease virus," Virus Genes, vol. 35, no. 3, pp. 635-642, 2007.

[7] A. Xin, H. Li, L. Li et al., "Genome analysis and development of infectious cDNA clone of a virulence-attenuated strain of footand-mouth disease virus type Asia 1 from China," Veterinary Microbiology, vol. 138, no. 3-4, pp. 273-280, 2009.

[8] H. L. Bachrach, "Foot-and-mouth disease.," Annual Review of Microbiology, vol. 22, pp. 201-244, 1968.

[9] J. D. Thompson, T. J. Gibson, F. Plewniak, F. Jeanmougin, and D. G. Higgins, "The CLUSTAL X windows interface: flexible strategies for multiple sequence alignment aided by quality analysis tools," Nucleic Acids Research, vol. 25, no. 24, pp. 48764882, 1997.

[10] S. Kumar, K. Tamura, and M. Nei, "MEGA3: integrated software for Molecular Evolutionary Genetics Analysis and sequence alignment," Briefings in Bioinformatics, vol. 5, no. 2, pp. 150-163, 2004.

[11] E. Martinez-Salas, J. C. Saiz, M. Dávila, G. J. Belsham, and E. Domingo, "A single nucleotide substitution in the internal ribosome entry site of foot-and-mouth disease virus leads to enhanced cap-independent translation in vivo," Journal of Virology, vol. 67, no. 7, pp. 3748-3755, 1993.

[12] X. Cao, I. E. Bergmann, and E. Beck, "Comparison of the $5^{\prime}$ and $3^{\prime}$ untranslated genomic regions of virulent and attenuated foot-and-mouth disease viruses (strains $\mathrm{O}_{1}$ Campos and $\mathrm{C}_{3}$ Resende)," Journal of General Virology, vol. 72, no. 11, pp. 28212825, 1991.

[13] P. Serrano, M. Pulido Rodriguez, M. Saiz, and E. MartínezSalas, "The 3 ' end of the foot-and-mouth disease virus genome establishes two distinct long-range RNA-RNA interactions with the $5^{\prime}$ and region," Journal of General Virology, vol. 87, no. 10, pp. 3013-3022, 2006.

[14] M. Rodríguez Pulido, P. Serrano, M. Sáiz, and E. Martínez-Salas, "Foot-and-mouth disease virus infection induces proteolytic cleavage of PTB, eIF3a,b, and PABP RNA-binding proteins," Virology, vol. 364, no. 2, pp. 466-474, 2007.
[15] T. R. Sweeney, N. Roqué-Rosell, J. R. Birtley, R. J. Leatherbarrow, and S. Curry, "Structural and mutagenic analysis of foot-andmouth disease virus $3 \mathrm{C}$ protease reveals the role of the $\beta$-ribbon in proteolysis," Journal of Virology, vol. 81, no. 1, pp. 115-124, 2007.

[16] P. W. Mason, M. J. Grubman, and B. Baxt, "Molecular basis of pathogenesis of FMDV," Virus Research, vol. 91, no. 1, pp. 9-32, 2003.

[17] S. Paul and T. Michiels, "Cardiovirus leader proteins are functionally interchangeable and have evolved to adapt to virus replication fitness," Journal of General Virology, vol. 87, no. 5, pp. 1237-1246, 2006.

[18] S. Tracy, N. M. Chapman, K. M. Drescher, K. Kono, and W. Tapprich, "Evolution of virulence in picornaviruses," Current Topics in Microbiology and Immunology, vol. 299, pp. 193-209, 2006.

[19] J. L. Whitton, C. T. Cornell, and R. Feuer, "Host and virus determinants of picornavirus pathogenesis and tropism," Nature Reviews Microbiology, vol. 3, no. 10, pp. 765-776, 2005.

[20] M. E. Piccone, F. D.-S. Segundo, E. Kramer, L. L. Rodriguez, and T. de los Santos, "Introduction of tag epitopes in the inter-AUG region of foot and mouth disease virus: effect on the L protein," Virus Research, vol. 155, no. 1, pp. 91-97, 2011.

[21] P. W. Mason, M. E. Piccone, T. S. McKenna, J. Chinsangaram, and M. J. Grubman, "Evaluation of a live-attenuated foot-andmouth disease virus as a vaccine candidate," Virology, vol. 227, no. 1, pp. 96-102, 1997.

[22] J. Chinsangaram, P. W. Mason, and M. J. Grubman, "Protection of swine by live and inactivated vaccines prepared from a leader proteinase-deficient serotype A12 foot-and-mouth disease virus," Vaccine, vol. 16, no. 16, pp. 1516-1522, 1998.

[23] M. J. Grubman, M. P. Moraes, F. Diaz-San Segundo, L. Pena, and T. De Los Santos, "Evading the host immune response: how foot-and-mouth disease virus has become an effective pathogen," FEMS Immunology and Medical Microbiology, vol. 53, no. 1, pp. 8-17, 2008.

[24] T. de Los Santos, S. de Avila Botton, R. Weiblen, and M. J. Grubman, "The leader proteinase of foot-and-mouth disease virus inhibits the induction of beta interferon mRNA and blocks the host innate immune response," Journal of Virology, vol. 80, no. 4, pp. 1906-1914, 2006.

[25] T. De Los Santos, F. D.-S. Segundo, J. Zhu, M. Koster, C. C. A. Dias, and M. J. Grubman, "A conserved domain in the leader proteinase of foot-and-mouth disease virus is required for proper subcellular localization and function," Journal of Virology, vol. 83, no. 4, pp. 1800-1810, 2009.

[26] C. Mayer, D. Neubauer, A. T. Nchinda, R. Cencic, K. Trompf, and T. Skern, "Residue L143 of the foot-and-mouth disease virus leader proteinase is a determinant of cleavage specificity," Journal of Virology, vol. 82, no. 9, pp. 4656-4659, 2008.

[27] M. Doherty, D. Todd, N. McFerran, and E. M. Hoey, "Sequence analysis of a porcine enterovirus serotype 1 isolate: relationships with other picornaviruses," Journal of General Virology, vol. 80, no. 8, pp. 1929-1941, 1999.

[28] Y. Kaku, S. Yamada, and Y. Murakami, "Sequence determination and phylogenetic analysis of RNA-dependent RNA polymerase (RdRp) of the porcine enterovirus 1 (PEV-1) Talfan strain," Archives of Virology, vol. 144, no. 9, pp. 1845-1852, 1999.

[29] C. Carrillo, E. R. Tulman, G. Delhon et al., "Comparative genomics of foot-and-mouth disease virus," Journal of Virology, vol. 79, no. 10, pp. 6487-6504, 2005. 
[30] M. George, R. Venkataramanan, B. Pattnaik et al., "Sequence analysis of the RNA polymerase gene of foot-and-mouth disease virus serotype Asia 1," Virus Genes, vol. 22, no. 1, pp. 21-26, 2001.

[31] J. Zeng, H. Wang, X. Xie et al., "Ribavirin-resistant variants of foot-and-mouth disease virus: the effect of restricted quasispecies diversity on viral virulence," Journal of Virology, vol. 88, no. 8, pp. 4008-4020, 2014.

[32] M. V. Borca, J. M. Pacheco, L. G. Holinka et al., "Role of arginine-56 within the structural protein VP3 of foot-andmouth disease virus (FMDV) O1 Campos in virus virulence," Virology, vol. 422, no. 1, pp. 37-45, 2012.

[33] A. Wigdorovitz, D. M. Pérez Filgueira, N. Robertson et al., "Protection of mice against challenge with foot and mouth disease virus (FMDV) by immunization with foliar extracts from plants infected with recombinant tobacco mosaic virus expressing the FMDV structural protein VP1," Virology, vol. 264, no. 1, pp. 85-91, 1999.

[34] S. Curry, E. Fry, W. Blakemore et al., "Dissecting the roles of VP0 cleavage and RNA packaging in picornavirus capsid stabilization: the structure of empty capsids of foot-and-mouth disease virus," Journal of Virology, vol. 71, no. 12, pp. 9743-9752, 1997.

[35] A. Bøtner, N. K. Kakker, C. Barbezange, S. Berryman, T. Jackson, and G. J. Belsham, "Capsid proteins from field strains of foot-and-mouth disease virus confer a pathogenic phenotype in cattle on an attenuated, cell-culture-adapted virus," Journal of General Virology, vol. 92, no. 5, pp. 1141-1151, 2011.

[36] J. I. Nunez, N. Molina, E. Baranowski et al., "Guinea pig-adapted foot-and-mouth disease virus with altered receptor recognition can productively infect a natural host," Journal of Virology, vol. 81, no. 16, pp. 8497-8506, 2007.

[37] M. Gutiérrez-Rivas, M. R. Pulido, E. Baranowski, F. Sobrino, and M. Sáiz, "Tolerance to mutations in the foot-and-mouth disease virus integrin-binding RGD region is different in cultured cells and in vivo and depends on the capsid sequence context," Journal of General Virology, vol. 89, no. 10, pp. 25312539, 2008.

[38] M. G. Mateu, M. Luz Valero, D. Andreu, and E. Domingo, "Systematic replacement of amino acid residues within an ArgGly-Asp-containing loop of foot-and-mouth disease virus and effect on cell recognition," Journal of Biological Chemistry, vol. 271, no. 22, pp. 12814-12819, 1996.

[39] M. Tesar, H.-G. Berger, and O. Marquardt, "Serological probes for some foot-and-mouth disease virus nonstructural proteins," Virus Genes, vol. 3, no. 1, pp. 29-44, 1989.

[40] S. U. Emerson, Y. K. Huang, H. Nguyen et al., "Identification of $\mathrm{VP} 1 / 2 \mathrm{~A}$ and $2 \mathrm{C}$ as virulence genes of hepatitis $\mathrm{A}$ virus and demonstration of genetic instability of 2C," Journal of Virology, vol. 76, no. 17, pp. 8551-8559, 2002.

[41] J. I. Núñez, E. Baranowski, N. Molina et al., "A single amino acid substitution in nonstructural protein $3 \mathrm{~A}$ can mediate adaptation of foot-and-mouth disease virus to the guinea pig," Journal of Virology, vol. 75, no. 8, pp. 3977-3983, 2001.

[42] A. Arias, C. Perales, C. Escarmís, and E. Domingo, "Deletion mutants of VPg reveal new cytopathology determinants in a picornavirus," PLoS ONE, vol. 5, no. 5, Article ID e10735, 2010.

[43] A. Xin, L. Li, M. Zhu et al., "Whole genome sequencing of a candidate strain for FMDV vaccine: genomic structure and genetic variation," Molecular Pathogens, vol. 2, no. 1, 2011.
[44] A. T. Giraudo, E. Beck, K. Strebel et al., "Identification of a nucleotide deletion in parts of polypeptide $3 \mathrm{~A}$ in two independent attenuated aphthovirus strains," Virology, vol. 177, no. 2, pp. 780-783, 1990.

[45] C. W. Beard and P. W. Mason, "Genetic determinants of altered virulence of Taiwanese foot-and-mouth disease virus," Journal of Virology, vol. 74, no. 2, pp. 987-991, 2000.

[46] J. M. Pacheco, T. M. Henry, V. K. O’Donnell, J. B. Gregory, and P. W. Mason, "Role of nonstructural proteins $3 \mathrm{~A}$ and $3 \mathrm{~B}$ in host range and pathogenicity of foot-and-mouth disease virus," Journal of Virology, vol. 77, no. 24, pp. 13017-13027, 2003.

[47] J. M. Pacheco, D. P. Gladue, L. G. Holinka et al., "A partial deletion in non-structural protein $3 \mathrm{~A}$ can attenuate foot-andmouth disease virus in cattle," Virology, vol. 446, no. 1-2, pp. 260-267, 2013. 

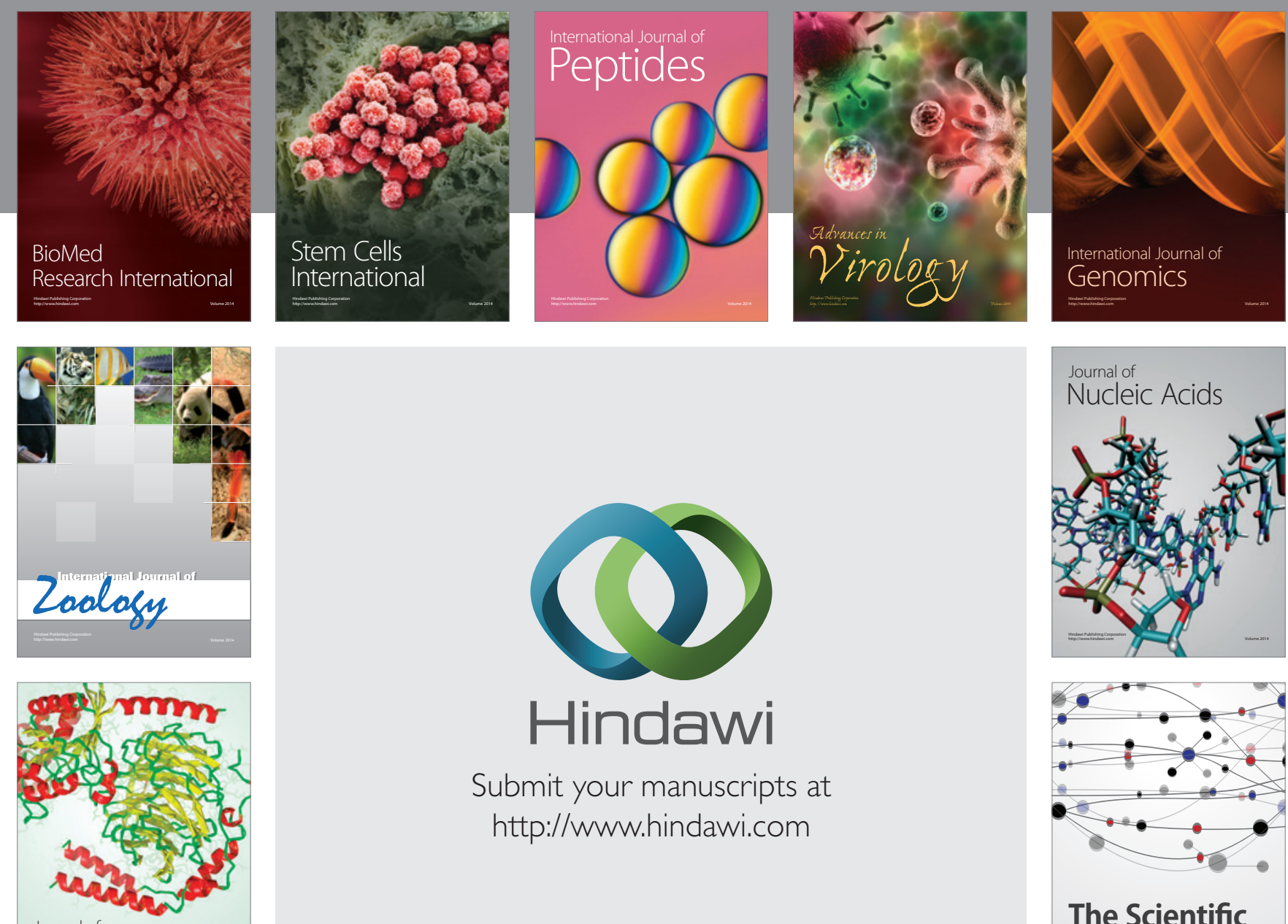

Submit your manuscripts at

http://www.hindawi.com

Journal of
Signal Transduction


The Scientific World Journal
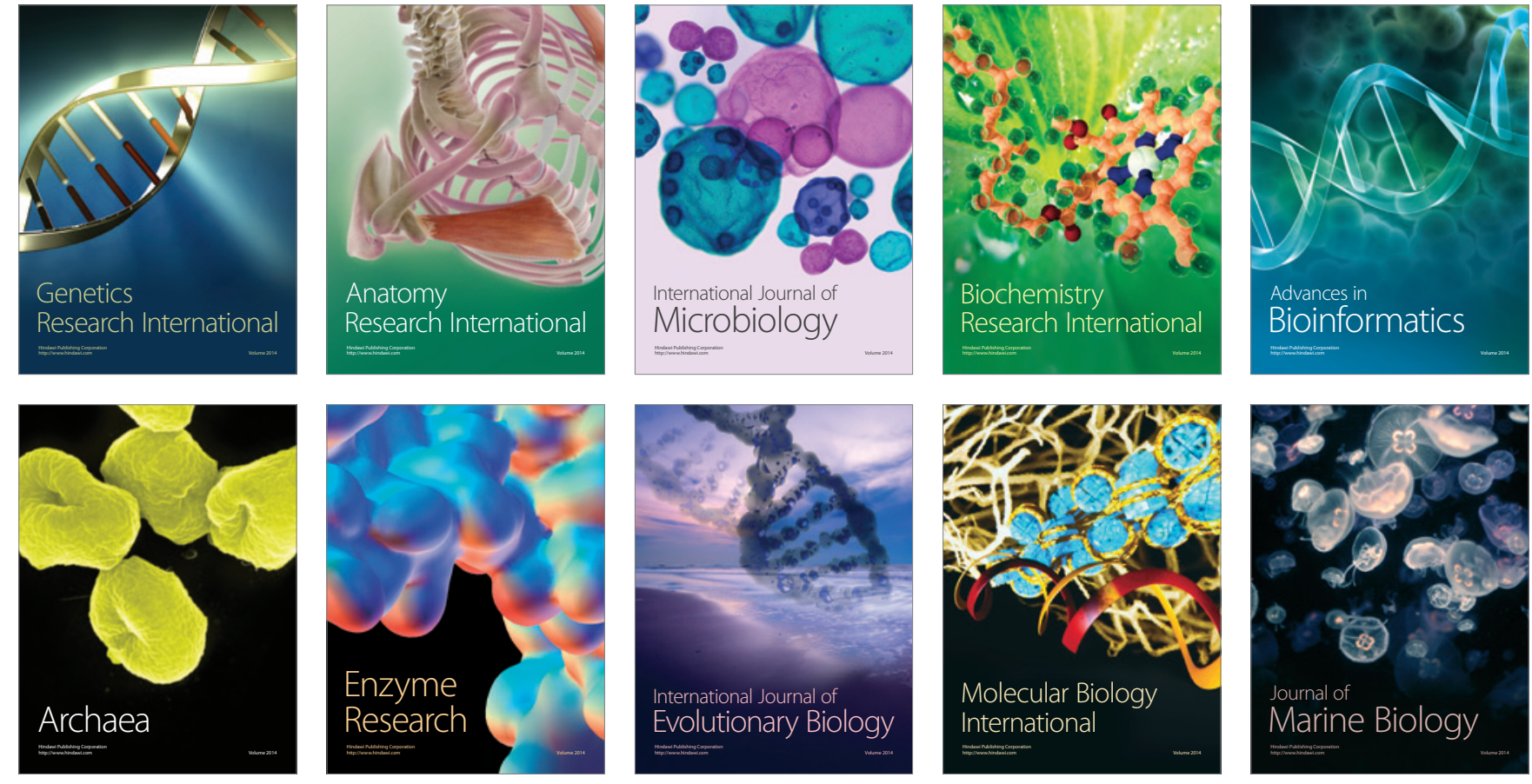